\title{
CPG15 regulates synapse stability in the developing and adult brain
}

\author{
Tadahiro Fujino, ${ }^{1}$ Jennifer H. Leslie, ${ }^{1,2}$ Ronen Eavri, ${ }^{1}$ Jerry L. Chen, ${ }^{1,2}$ Walter C. Lin ${ }^{1,3}$ \\ Genevieve H. Flanders, ${ }^{1}$ Erzsebet Borok, ${ }^{4,5}$ Tamas L. Horvath, ${ }^{4,5}$ and Elly Nedivi ${ }^{1,2,3,6}$ \\ ${ }^{1}$ The Picower Institute for Learning and Memory, ${ }^{2}$ Department of Biology, ${ }^{3}$ Department of Brain and Cognitive Sciences, \\ Massachusetts Institute of Technology, Cambridge, Massachusetts 02139, USA; ${ }^{4}$ Department of Obstetrics, Gynecology, and \\ Reproductive Sciences, ${ }^{5}$ Department of Neurobiology, Division of Comparative Medicine, Yale University School of Medicine, \\ New Haven, Connecticut 06520, USA
}

Use-dependent selection of optimal connections is a key feature of neural circuit development and, in the mature brain, underlies functional adaptation, such as is required for learning and memory. Activity patterns guide circuit refinement through selective stabilization or elimination of specific neuronal branches and synapses. The molecular signals that mediate activity-dependent synapse and arbor stabilization and maintenance remain elusive. We report that knockout of the activity-regulated gene cpg15 in mice delays developmental maturation of axonal and dendritic arbors visualized by anterograde tracing and diolistic labeling, respectively. Electrophysiology shows that synaptic maturation is also delayed, and electron microscopy confirms that many dendritic spines initially lack functional synaptic contacts. While circuits eventually develop, in vivo imaging reveals that spine maintenance is compromised in the adult, leading to a gradual attrition in spine numbers. Loss of $\operatorname{cpg} 15$ also results in poor learning. cpg15 knockout mice require more trails to learn, but once they learn, memories are retained. Our findings suggest that CPG15 acts to stabilize active synapses on dendritic spines, resulting in selective spine and arbor stabilization and synaptic maturation, and that synapse stabilization mediated by CPG15 is critical for efficient learning.

[Keywords: mouse; brain; synapse; dendrite; two-photon microscopy; learning]

Supplemental material is available for this article.

Received August 4, 2011; revised version accepted November 1, 2011.

During development, neuronal processes extend and retract as they explore their environment to identify appropriate synaptic partners. The establishment of pre- and post-synaptic contact is an early event in an ordered progression that can lead to formation of stable mature synapses. It has been proposed that synapse formation consequently acts as a stabilizing force on growing axonal and dendritic processes (Meyer and Smith 2006; Ruthazer et al. 2006). While studies have delineated some aspects of synaptogenesis and synaptic maturation (McAllister 2007), the signals at the contact point of axon and dendrite that determine whether a synapse will stabilize and persist have not been fully elucidated.

Although excitatory synaptogenesis can occur in the absence of neural activity (Gomperts et al. 2000; Verhage et al. 2000), strong evidence suggests that experience plays a critical role in biasing the formation and stabilization of synapses that transmit appropriately patterned activity (Hua and Smith 2004) and that NMDA-type glutamate

${ }^{6}$ Corresponding author.

E-mail nedivi@mit.edu.

Article is online at http://www.genesdev.org/cgi/doi/10.1101/gad.176172.111. receptors mediate this activity-dependent synapse selection (Gomperts et al. 2000). Activation of NMDA receptors allows $\mathrm{Ca}^{+2}$ influx into the post-synaptic cell, turning on kinase signaling cascades, which in turn initiate transcription factor activation and new gene expression (for reviews, see Flavell and Greenberg 2008; Loebrich and Nedivi 2009|. Yet, how this set of events leads to local implementation of synaptic stabilization is not clear. In fact, little is known about the molecular mechanisms regulating selective synapse and dendrite stabilization in response to activity.

cpg15 (also termed neuritin) was first identified in a screen for activity-regulated genes in rats (Nedivi et al. 1993; Hevroni et al. 1998) and is a downstream target of the classic synaptic plasticity signaling cascade, involving the NMDA receptor, MAPK, CaMK, and CREB (Fujino et al. 2003). During development, cpg15 expression is induced in presynaptic neurons upon contact with their target (Diaz et al. 2002) and is spatially and temporally correlated with synapse formation and activity-dependent plasticity (Nedivi et al. 1996; Corriveau et al. 1999; Lee and Nedivi 2002). cpg15 encodes a small extracellular protein anchored to the cell surface via a glycosyl-phosphoinositide 
(GPI) link (Naeve et al. 1997). CPG15 overexpression in the developing Xenopus enhances dendritic and axonal elaboration in a non-cell-autonomous manner, as well as synapse formation and maturation (Nedivi et al. 1998; Cantallops et al. 2000; Javaherian and Cline 2005).

To investigate the requirement for CPG15 in a mammalian system, we generated a knockout mouse for $\operatorname{cpg} 15$ (cpg15 KO). We found that in the cpg15 KO, there is a developmental delay in axonal and dendritic arborization and maturation of excitatory synapses. In the dentate gyrus (DG) of the hippocampus, as many as $30 \%$ of spines initially lack synapses. Chronic in vivo imaging of cortical pyramidal neurons through a cranial window shows that while dendritic spine dynamics in $\operatorname{cpg} 15 \mathrm{KO}$ mice are comparable with controls, fewer events in these mice are stabilized and thus favor persistent spine loss. These results suggest that the in vivo developmental deficits in the cpg15 KO mouse derive from lack of a synaptic stabilization signal, perhaps supplied in an activity-dependent manner. While adult circuits appear normal, they are functionally suboptimal, leading to poor performance in learning tasks. These findings establish a role for CPG15 in efficient circuit formation and function and provide a potential molecular mechanism for selective synapse stabilization.

\section{Results}

\section{Generation of a cpg15 KO mouse}

To investigate the in vivo role of $\operatorname{cpg} 15$, we generated a mouse lacking cpg15 using a conditional knockout approach based on the Cre-lox $P$ system. We first made a "floxed" cpg15 mouse with loxP sites flanking cpg15 exons two and three (Fig. 1A). Exons two and three contain the entire coding sequence for the mature form of CPG15, and excision of the sequence between the lox $P$ sites by Cre recombinase would generate a null mutation. Floxed cpg15 mice were crossed to a global Cre deleter line that expresses Cre recombinase in all tissues, including the germline (Lakso et al. 1996), to obtain general cpg15-null mice (cpg15 KO mice). Southern blotting showed successful homologous recombination in the floxed $\operatorname{cpg} 15$ mouse and Cre excision in the cpg15-null mouse (Fig. 1B). Northern blotting and Western blotting confirmed the absence of $\operatorname{cpg} 15$ mRNA and CPG15 protein in the brains of $\operatorname{cpg} 15 \mathrm{KO}$ mice (Fig. 1C,D).

Homozygous cpg15 KO mice were born at a Mendelian ratio and showed no overt behavioral abnormalities. Their muscle strength and motor coordination were also normal (Supplemental Fig. S1A,B). cpg15 KO mice were leaner than wild-type littermates, with a body length $3 \%$ shorter, and, on average, weighed $20 \%-30 \%$ less (Supplemental Table S1). cpg15 KO brains were similar in weight and size to wild-type brains, although the cerebellum tended to be slightly smaller (Supplemental Table S1). The anatomy of Nissl-stained $\operatorname{cpg} 15 \mathrm{KO}$ brains at $8 \mathrm{wk}$ of age appeared normal (Fig. 1E). Neocortical volume, cell density, and total cell number were similar between wildtype and cpg15 KO mice (Supplemental Table S1).
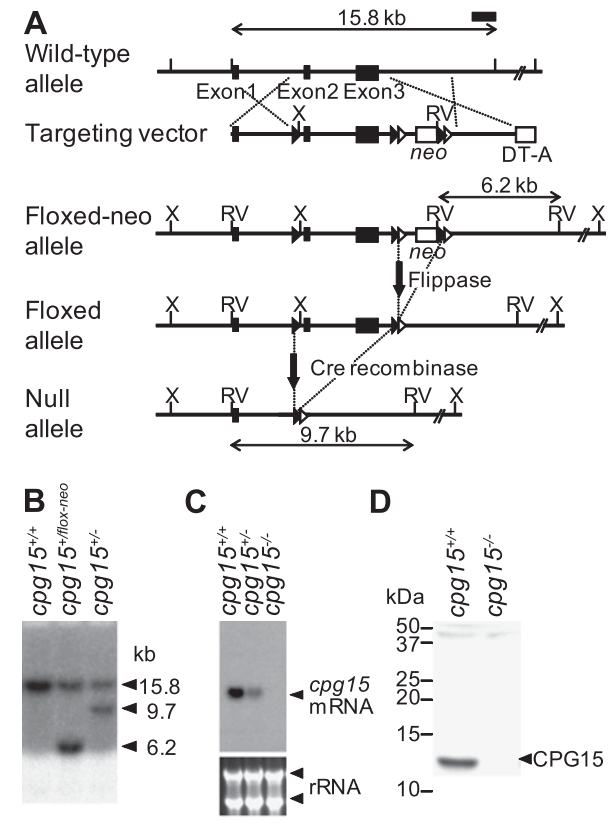

E

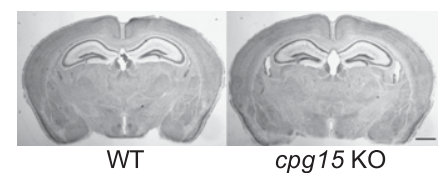

Figure 1. Generation of the cpg15 KO mouse. (A) Schematic drawing of the wild-type (WT) cpg15 allele, the targeting vector, the floxed allele with the neomycin-resistant gene (neo), the floxed allele without neo, and the null allele. Indicated are three cpg15 exons (closed boxes); the neo and the diphtheria toxin A gene (DT-A) serving as positive and negative selection markers, respectively (open boxes); lox $P$ sites (closed triangles); FRT sites (open triangles); and XhoI (X) and EcoRV (RV) restriction sites. Homologous recombination between the wild-type allele and the targeting vector generated a floxed neo allele and eliminated the DT-A gene. The neo gene flanked by two FRT sites was deleted by injection of flippase RNA into eggs harvested from the floxed neo mice. Mice after flippase recombination were crossed with a Cre deleter line to generate the cpg15-null allele. Positions of the 3 ' probe used for Southern blot analysis and expected band sizes are indicated. (B) Southern blot analysis of wild-type $\left(\operatorname{cpg} 15^{+/+}\right)$, heterozygous floxed $\left(\operatorname{cpg} 15^{+/ \text {flox-neo }}\right)$, and heterozygous null $\left(\mathrm{cpg} 15^{+/-}\right)$ mice. Genomic DNA was digested with EcoRV and probed with the 3 ' probe shown in $A$. In addition to the wild-type $15.8-\mathrm{kb}$ band, the floxed neo mouse shows a $6.2-\mathrm{kb}$ band and the null mouse shows a 9.7-kb band, as expected. $(C)$ Northern blot analysis of brain RNA from wild-type, heterozygous, and homozygous null mice probed with cpg15 cDNA. Ribosomal RNA (rRNA) is shown as a loading control. $(D)$ Western blot analysis of brain extracts from wild-type and homozygous null mice probed with an antiCPG15 antibody. $(E)$ Nissl-stained coronal sections from wild-type and cpg15 KO mice. Bar, $1 \mathrm{~mm}$.

\section{Delayed axonal and dendritic arbor development in cpg15 KO mice}

In the developing Xenopus, CPG15 overexpression promotes arborization of retinal ganglion cell axonal projections in the tectum by reducing branch retractions (Cantallops et al. 2000). To test for deficits in axon arbor 
development in $\operatorname{cpg} 15 \mathrm{KO}$ mice, we bulk-labeled retinal ganglion cell projections as these axons were growing and elaborating their arbors in the lateral geniculate nucleus (LGN) of the thalamus by injecting each eye with an anterograde tracer conjugated to a different fluorophore. In wild-type mice, the total area of LGN covered by projections from both eyes increased dramatically between postnatal day 4 (P4) and P21 (Fig. 2A,B). Since neuronal proliferation in the LGN occurs during embryogenesis (Brückner et al. 1976), the postnatal increase in LGN volume is largely due to axon ingrowth and elaboration of both the axonal and dendritic neuropil. In the cpg15 KO mice, the retinogeniculate projection area is similar in size to that of wild-type mice at P4, but the projection area does not grow to the same extent as controls by P9 (Fig. 2A,B). LGN cell count and density in the cpg15 KO mice at P9 were comparable with controls (Supplemental Table S2), suggesting that the difference in projection areas at this age is not due to a decrease in LGN cell numbers, but rather delayed development of the neuropil, including retinal ganglion cell axons and LGN cell dendrites. By P90, the retinogeniculate projection area was indistinguishable between genotypes, with similar levels of segregation of ipsilateral and contralateral arbors, as measured by the degree of overlap (Fig. 2C). While the delay in retinogeniculate projection development in the LGN of $\operatorname{cpg} 15 \mathrm{KO}$ mice indicates that there may be deficits in axonal and perhaps dendritic elaboration, the normal appearance of the LGN at P90 suggests that these deficits are overcome with age.

CPG15 overexpression studies showing enhanced dendritic arborization (Nedivi et al. 1998) and the potential delay in LGN neuropil development seen in cpg15 KO mice led us to examine whether dendritic arbor development was also delayed in cpg15 KO neurons. Using diolistic labeling (Grutzendler et al. 2003), we visualized neurons in the granule cell layer of the DG of the hippocampus (Fig. 3A), a region that normally shows high cpg15 expression throughout development and has been extensively characterized in the context of synaptic plasticity and paradigms of learning and memory.

Granule cell dendritic arbors in the hippocampal DG predominantly develop in two stages (Rahimi and Claiborne 2007). The bulk of neurogenesis occurs embryonically through P14, peaking during the second postnatal week, with the majority of cells born postnatally. During this period, granule cell dendritic trees are initially established. The second phase begins at the end of the second postnatal week and lasts until $\sim 2$ mo of age. It is during this time that the dendritic trees are sculpted and refined. At the onset of this second phase, granule cell dendritic trees have many segments, including short terminal branches, which are largely pruned by 2 mo. The remaining branches increase in length over this period, resulting in a conservation of total dendrite length but a reduction in segments and terminal ends. To assess the contribution of CPG15 at these two phases, we compared granule cell dendritic morphology in the cpg15 KO and wild-type littermates at P15 and P60. At P15, DG granule cells in the cpg15 KO showed significantly fewer branch tips per neuron as compared with wild type, suggesting an initial lack of complexity due to reduced numbers of short terminal branches. Between P15 and P60, we observed branch tip pruning that was more
A

P4
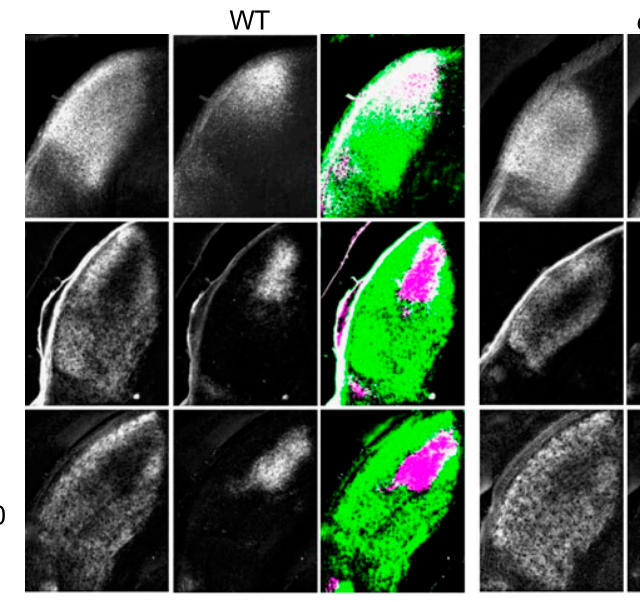

cpg $15 \mathrm{KO}$

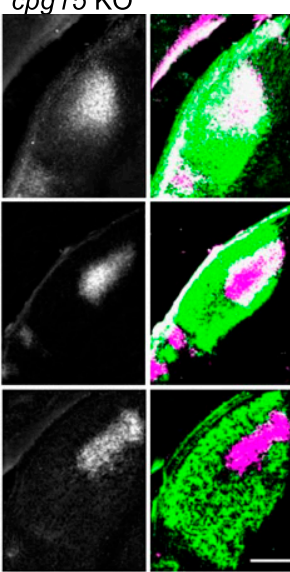

B

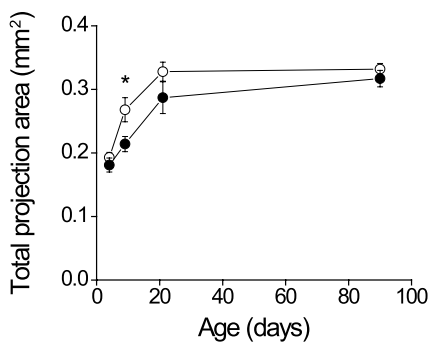

C

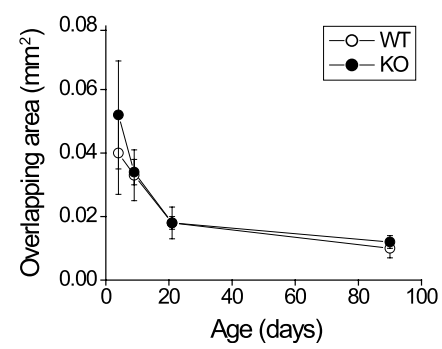

Figure 2. Delayed axon arbor development in the LGN of cpg15 KO mice. (A) Representative images of the dorsal LGN at different developmental times from wild-type (WT) and cpg15 KO mice injected in each eye with wheat germ agglutinin conjugated to different fluorophores. Projections from the contralateral eye (left), the ipsilateral eye (middle), and the merged image from both eyes (right) are shown. For merged images, all pixels above background were pseudo-colored in green for contralateral eye or magenta for ipsilateral eye. White indicates overlap. Notice the similar overlap but different size of labeled LGN at P9. (B) Age-dependent change in the total area of LGN covered by projections from both ipsilateral and contralateral eyes $\left(n=3\right.$ for P4, P9, and P21; $n=5$ for P90). ( $\left.{ }^{\star}\right) P$-value $<$ 0.05. (C) Age-dependent change in the area of overlap between projections from ipsilateral and contralateral eyes did not differ between genotypes. Bar, $200 \mathrm{~mm}$. 
A
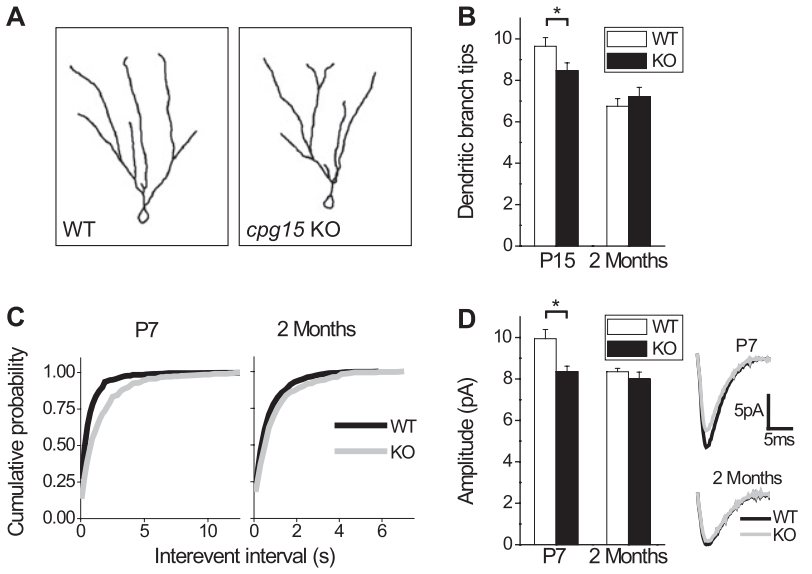

Figure 3. Delayed dendritic arbor and synapse development in DG of cpg15 KO mice. (A) Representative traces of reconstructed DG granule cells from the wild type (WT) (left) and cpg15 KO (right) at 2 mo of age. (B) Average number of dendritic branch tips per cell at P15 (left) $(n=39$ wild-type cells; $n=32$ knockout cells) and 2 mo (right) $(n=32$ cells for wild-type and knockout). $\left.{ }^{\star}{ }^{\star}\right) P$-value $<0.05$. (C) Cumulative probability plots of interevent intervals of mEPSCs of DG granule cells at ages P7 (left) ( $n=9$ wild-type cells; $n=7$ knockout cells; $P$-value $<0.001$ by K-S test) and 2 mo (right) ( $n=13$ wild-type cells; $n=7$ knockout cells; $P$-value $=0.003$ by K-S test $).(D)$ Average mEPSC amplitudes of DG granule cells at ages P7 (left) $(n=9$ wild-type cells; $n=7$ knockout cells) and 2 mo (right) $n=13$ wild-type cells; $n=7$ knockout cells). (Right inset) Averaged mEPSCs are plotted for both ages. $\left(^{\star}\right) P$-value $=0.01$.

pronounced in the wild type as compared with knockout animals, such that the difference between them was diminished by 2 mo of age and dendritic arbors appeared normal (Fig. 3B). This is similar to our findings regarding neuropil development in the LGN.

\section{Delayed synaptic development and maturation in cpg15 KO mice}

Next, we tested for deficits in the $\operatorname{cpg} 15 \mathrm{KO}$ that might derive from the effects of CPG15 on synapse formation and maturation. We examined formation of functional synapses by performing whole-cell patch clamp recordings in the granule cell layer of the DG in acute hippocampal slices and recorded spontaneous miniature post-synaptic currents (mEPSCs) (Fig. 3C). We found that in the DG of cpg15 KO mice at P7, mEPSCs occur with lower frequency. This deficit persisted at 2 mo of age, but was less significant (Fig. 3C). In the P7 DG of cpg15 KO mice, mEPSC amplitudes were also reduced; however, this deficit was no longer observed by $2 \mathrm{mo}$ of age (Fig. 3D). These results suggest that during development, cpg15 KO mice have fewer and less mature functional synapses.

To examine the synaptic structural correlates of reduced mEPSC frequency and amplitude in the developing hippocampus, we performed electron microscopy (EM) in different subfields of the hippocampal formation. No apparent qualitative differences in synaptic structure were seen in any of these areas, as assessed by the presence of presynaptic terminal zones with vesicles and apposed post-synaptic densities (PSDs) (Fig. 4A). However, when the density of asymmetric synapses on dendritic spines was measured by unbiased stereology, we found that cpg15 KO mice had spine synapse densities in the DG that were $26 \%$ lower than wild-type controls at 2 mo of age (Fig. 4B). This change appeared specific to the DG and was not observed in CAl at this age. The decrease in DG spine density correlates with our findings of decreased mEPSC frequency in the cpg 15 KO DG (Fig. 3C) but not in
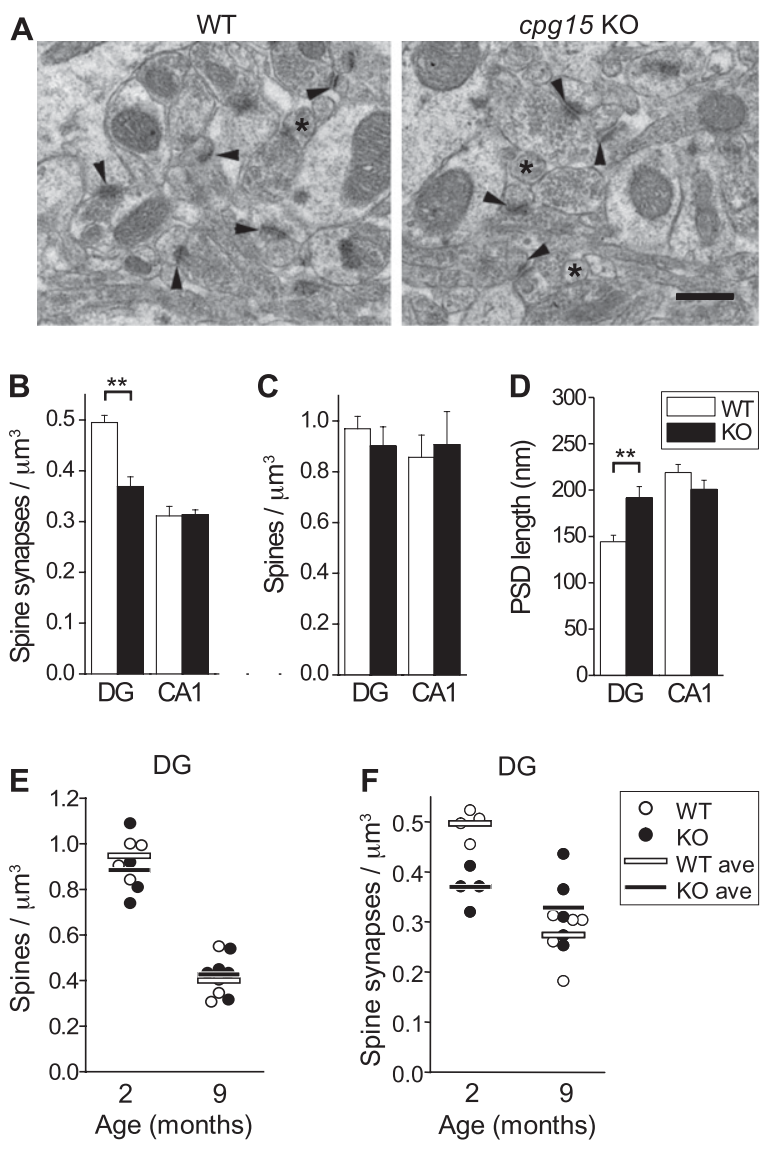

Figure 4. Delayed spine synapse development and lack of agedependent synaptic pruning in cpg15 KO mice. $(A)$ Representative EM images from the molecular layer of the DG of wild-type (WT) and cpg15 KO mice. Arrowheads indicate spine synapses, and asterisks mark spine or spine-like protrusions. Spine synapse density $(B)$, spine or spine-like protrusion density $(C)$, and PSD length $(D)$ of indicated regions $(n=4$ mice for wild type and

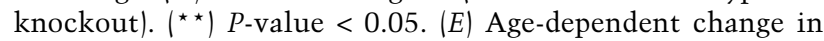
spine density of DG region. Spine density per mouse is represented by circles, and the average for each genotype is indicated by a horizontal line $(n=4$ mice each for wild type and knockout at $2 \mathrm{mo} ; n=4$ mice for wild-type and $n=5$ mice for knockout at 9 mo). $P$-value $<0.001$ for 2 mo versus 9 mo for wild-type and knockout DG. $(F)$ Age-dependent change in spine synapse density in the DG region. Spine synapse density per mouse is represented by circles, and the average for each genotype is indicated by a horizontal line $(n=4$ mice for $2 \mathrm{mo}$ and $n=5$ mice for 9 mo for wild type and knockout). $P$-value $<0.001$ for 2 mo versus 9 mo for wild type; n.s. for knockout. Bar, $1 \mathrm{~mm}$. 
CA1 (Supplemental Fig. S2) at 2 mo of age and may be due to late development of the DG as compared with other hippocampal regions. Interestingly, when we measured the density of spines and spine-like protrusions at 2 mo regardless of whether they contained a synaptic specialization, there were no significant differences between cpg15 KO mice and wild-type controls even in the DG (Fig. 4C). These results suggest that in the developing DG of the cpg15 KO, a large fraction of spine-like protrusions lack a synaptic structure. EM examination of synapse size at 2 mo, as measured by PSD length, showed that PSDs of cpg15 KO mice were $33 \%$ larger than those of wild-type mice in the DG but not in CA1 (Fig. 4D). Perhaps the increased synapse size is a compensatory response to the decrease in spine synapse numbers in the DG of cpg15 KO mice.

In the retinogeniculate pathway as well as the hippocampus, neuropil development in the cpg15 KO is initially delayed but eventually reaches wild-type levels. We examined whether the deficit in dendritic spine synapse number also recovers with age by comparing spine and spine synapse densities between 2- and 9-mo-old cpg15 KO mice and wild-type littermates. Between 2 and 9 mo, both cpg15 KO mice and wild-type controls prune spines in a similar manner (Fig. 4E). Wild-type controls also prune spine synapses over this period, consistent with ongoing synapse remodeling and refinement (Markus and Petit 1987). However, cpg15 KO synapse density, which starts out lower than wild type at $2 \mathrm{mo}$, is not further reduced by 9 mo of age and remains relatively constant during this period (Fig. 4F). Thus, we see that neurons in the late developing DG of cpg15 KO mice initially form fewer spine synapses than wild-type neurons. Over time, these synapses are less likely to be pruned, so that by $9 \mathrm{mo}$, synapse numbers are similar in wild type and knockout.

\section{Increased loss of persistent spines in cpg15 KO mice}

In vivo imaging studies followed by EM have demonstrated that spine sprouting and retraction are associated with synapse formation and elimination (Trachtenberg et al. 2002; Knott et al. 2006) and that synaptogenesis is inversely correlated with spine motility (Konur and Yuste 2004). In light of the unusually large fraction of dendritic spines lacking synapses in the developing DG of cpg15 KO mice, we asked whether CPG15 depletion also affects dendritic spine dynamics. To this purpose, we performed in vivo imaging of neurons in the visual cortices of adult cpg15 KO mice. The cortex was chosen to assay spine dynamics because it is optically accessible via implantation of cranial windows, allowing chronic monitoring of spine dynamics. In addition, previous studies have shown that even in the adult cortex, a significant fraction of dendritic spines remain dynamic, with the majority of events being either transient spine additions or reversible eliminations (Holtmaat et al. 2005, 2006). Persistentdynamic events, including spines that emerge and persist (new-persistent spines) as well as spines that disappear and do not re-emerge (lost-persistent spines), likely best represent events that correspond to synapse formation and elimination (Holtmaat et al. 2005, 2006).
We generated cpg15 KO mice expressing GFP in a random subset of neurons sparsely distributed within the neocortical layers by crossing the thy1-GFP-S line that expresses GFP in a random subset of neocortical neurons (Feng et al. 2000; Lee et al. 2006) to the cpg15 KO (see the Materials and Methods). Adult thy1-GFP/cpg15 KO mice (homozygous for thy1-GFP and $c p g 15^{-/-}$) and thy1-GFP littermate controls were surgically implanted with bilateral cranial windows over the visual cortices. Following 3 wk of recovery, layer 5 (L5) pyramidal neurons were identified, and a two-photon imaging volume encompassing their apical tufts in L1 was acquired at 4-d intervals (Fig. 5A). We found that the total rate of dynamic events, including both spine gain and loss, was not significantly different between wild-type and cpg15 KO mice (Fig. 5B). However, in the cpg15 KO, the percentage of dynamic events that persisted was significantly higher than in the wild type. Conversely, the percentage of transient events was significantly lower (persistent-dynamic: $69.23 \%$ for knockout, $55.06 \%$ for wild type; transient: $30.76 \%$ for knockout, $44.94 \%$ for wild type; $P$-value $<0.05$ ) (Fig. 5C). For both the wild type and $\operatorname{cpg} 15 \mathrm{KO}$, dynamic-persistent events that favor spine loss (lost-persistent) were higher than dynamic-persistent events that favor spine gain (newpersistent). However, this difference was more pronounced for the cpg15 KO (lost-persistent: $70.79 \%$ for knockout, $60.64 \%$ for wild type; new-persistent: $29.21 \%$ for knockout, $39.36 \%$ for wild type; $P$-value $<0.001$ for knockout; $P$-value $<0.05$ for wild type) (Fig. 5D). Since the cpg15 KO has a greater percentage of dynamic-persistent events overall, and persistent events favor loss, we observed a significant reduction in spine densities for individual cpg15 KO neurons over the course of the imaging period, which was not seen in wild-type neurons (Fig. 5E). Overall, these results suggest that loss of cpg15 leads to a decrease in spine stabilization, resulting in reduced maintenance of both newly formed and existing spines.

\section{Inefficient learning in cpg15 KO mice}

Given the contribution of activity-regulated genes to plasticity (Leslie and Nedivi 2011), we next examined whether the deficits in cellular development and spine stabilization seen in cpg $15 \mathrm{KO}$ mice impacted behavioral plasticity in the adult, such as learning and memory. cpg15 KO mice were subjected to a fear conditioning test, a form of classical conditioning. Context-dependent fear conditioning is a hippocampal-dependent paradigm. We rationalized that due to cellular defects observed in the hippocampus, cpg15 KO mice may not perform as well as wild-type counterparts in this task. Mice were given a paired shock and tone in a conditioning chamber. Afterward, they were returned to the same chamber to test for contextual memory or were presented with the same tone in a different context to test for tone-dependent memory. Surprisingly, cpg15 KO mice exhibited less freezing than wild-type controls in response to both context and tone (Fig. 6A), suggesting deficits in both contextual and tonedependent memory. Interestingly, cpg15 KO mice showed little freezing in response to context even $1 \mathrm{~h}$ after training, 


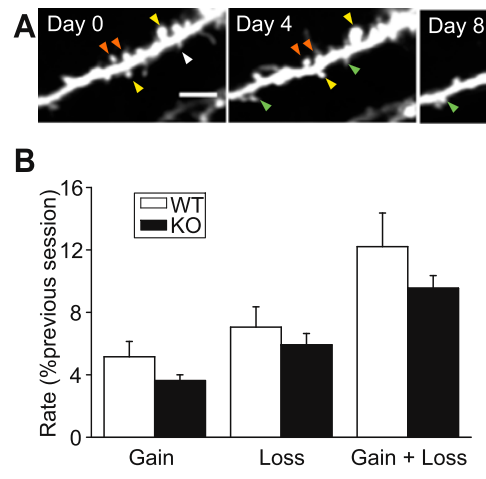

D

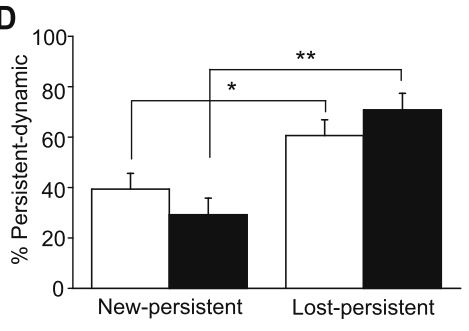

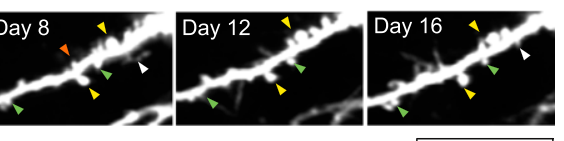

C

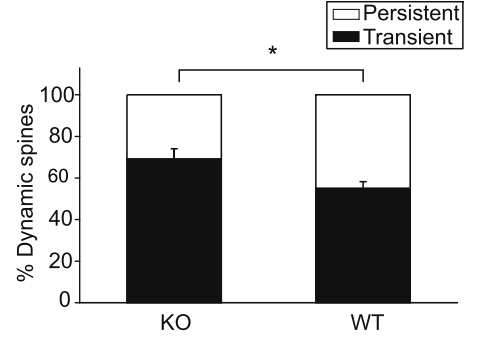

E

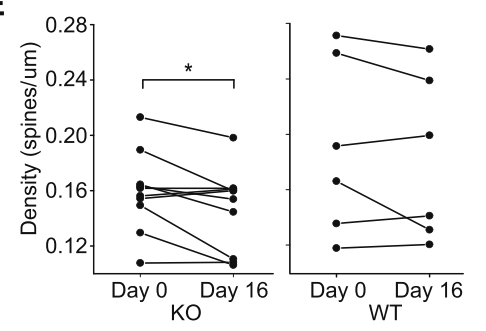

Figure 5. Repeated imaging of apical L5 cell dendrites in visual cortex of cpg15 KO and wild-type (WT) mice shows that dendritic spine dynamics in cpg15 KO neurons are weighed toward spine loss. (A) Representative example of a dendrite stretch showing persistent spines (yellow arrows), new-persistent spines (green arrows), lost-persistent spines (orange arrows), and transient spines (white arrows). (B) Averaged rates of spine gain and spine loss for all sessions ( $n=9$ knockout mice, 13 cells, 794 spines; $n=8$ wildtype mice, 16 cells, 847 spines). (C) Percentage of persistent-dynamic and transient spines out of total dynamic spines. Persistent-dynamic includes lost-persistent and new-persistent spines. $(n=9$ knockout mice, 13 cells, 794 spines; $n=6$ wild-type mice, 11 cells, 609 spines). ( $\left.{ }^{\star}\right) P$-value $<0.05$. (D) Percentage of new-persistent and lost-persistent spines out of total persistent-dynamic spines. $\left(^{\star}\right) P$-value $<0.05 ;{\left({ }^{\star \star}\right)}^{*}$ $P$-value $<0.001$. (E) Spine densities of individual animals between the first and fifth imaging sessions. Student's paired $t$-test, $\left(^{\star}\right) P$-value $<0.05$. Bar, $5 \mu \mathrm{m}$. suggesting impaired short-term memory. In this test, it was impossible to discriminate whether there was a true deficit in long-term memory or whether it was secondary to the short-term memory deficit. To address this question, mice were trained using repeated conditioning sessions on days $1,3,5$, and 7 and tested $1 \mathrm{~d}$ after each session on days $2,4,6$, and 8 . For tone-dependent memory, wildtype mice showed a robust freezing response after the first conditioning trial, with an additional small increase after the second trial (Fig. 6B). cpg15 KO mice showed little freezing after the first conditioning trial despite a slightly lower threshold for pain and higher anxiety than wild-type controls (Supplemental Fig. S1C,D), but showed a large increase after the second trial before reaching a plateau similar to wild-type controls by the third trial. To see whether stronger conditioning would improve learning, in the fourth conditioning session, three tone-shock pairs were given instead of one. This fourth conditioning session did not elicit increased freezing in either genotype, indicating saturation of the response. The repeated training experiment demonstrates that while cpg15 $\mathrm{KO}$ mice are slow to learn the task, they do have the basic sensory and motor functions to perform it and are able to form and retrieve long-term memories once they learn the task.

To see whether memory was stable on a longer time scale, we tested the mice 2 wk after conditioning by repeated training. Memory retention, calculated as the ratio of freezing at 2 wk to $1 \mathrm{~d}$ after completion of the repeated training trials, showed that cpg15 KO mice retained memory similarly to wild-type controls (Fig. 6C). In summary, cpg15 KO mice showed inefficient learning of fear memories. However, this impairment could be overcome by repeated training, and memory was stable once acquired.

To confirm that the learning deficit in cpg15 KO mice was not specific to the fear conditioning task, we also tested learning in the Morris water maze. The Morris water maze requires mice to locate a platform submerged in a pool using only visual or spatial cues. In the visible platform version of the Morris water maze, a visual cue is placed on the submerged platform so that mice can locate the platform based on this cue. This task does not require spatial memory, but does require mice to make certain associations, such as those between the visual cue and the platform, in addition to basic visual and motor abilities to perform the task.

During the $7 \mathrm{~d}$ of training, swim distance to reach the platform decreased for both wild-type and cpg $15 \mathrm{KO}$ mice, indicating that they were able to learn the task (Fig. 6D). However, cpg $15 \mathrm{KO}$ mice showed slower acquisition when compared with wild-type controls. The difference was most obvious on the second day of the training, when wild-type controls were close to their peak performance, but many of the cpg15 KO mice showed no improvement. Despite these deficits, improvement in performance and the directed swimming toward the platform after training suggests that cpg15 KO mice were able to recognize the visual cue. Thus, in the visible platform test, cpg15 KO mice showed slower acquisition of the task but improved with repeated training, similar to what we observed in the fear conditioning test.

\section{Discussion}

Here we show that a knockout mouse lacking cpg15 exhibits delayed axonal, dendritic, and synaptic development. Adult cpg15 KO mice display reduced spine maintenance, leading to gradual spine loss. Loss of cpg15 also has behavioral consequences, manifested as poor performance in learning tasks.

The finding that adult cpg15 KO mice have an apparently normal neocortex with regards to size and cell number was initially surprising, since acute RNAi-mediated knockdown in embryonic rat brains showed a requirement for CPG15 in cortical progenitor cell survival 

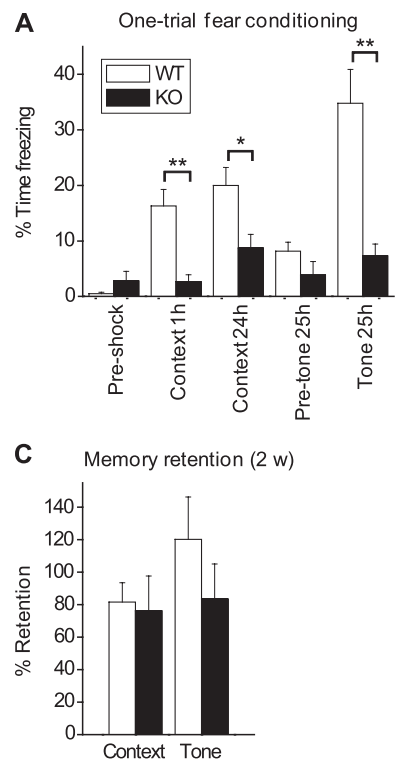
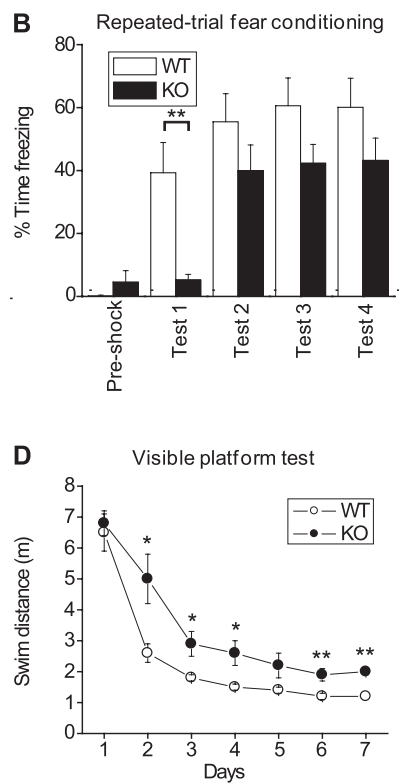

Figure 6. cpg15 KO mice show slow learning in fear conditioning and visible platform tests. $(A)$ Mice were given a paired tone and shock and then tested for contextual memory $1 \mathrm{~h}$ and $24 \mathrm{~h}$ later and for tone-dependent memory at $25 \mathrm{~h}$ after the shock. Fear memory is measured as percentage of time spent freezing ( $n=23$ for wild type; $n=27$ for knockout). $\left({ }^{\star}\right) P$-value $<$ $\left.0.05 ;{ }^{* \star}\right) P$-value $<0.01$. (B) Freezing response to tone after repeated training. Mice were given tone-shock pairings every other day and were tested $1 \mathrm{~d}$ after each training session $(n=10$ for wild type and knockout). $\left(^{\star \star}\right) P$-value $<0.01$. (C) Fear conditioning is stable for at least $2 \mathrm{wk}$. Mice were tested at 1 $\mathrm{d}$ and $2 \mathrm{wk}$ after the repeated training shown in $B$. Percentage of retention was calculated as the ratio in freezing time at $2 \mathrm{wk}$ to $1 \mathrm{~d}$ after training and was averaged for each genotype. Some mice showed longer freezing times at $2 \mathrm{wk}$, resulting in some retention scores $>100 \%$ ( $n=10$ for wild type and knockout). (D) Swim distance with repeated training in the Morris water maze visible platform test ( $n=12$ for wild type and knockout). $\left({ }^{*}\right)$ $P$-value $<0.05 ;{ }^{\star \star} \mid P$-value $<0.001$.

(Putz et al. 2005). We were also surprised that despite the robust effect of CPG15 overexpression on dendritic and axonal arbor growth in the developing Xenopus retinotectal system (Nedivi et al. 1998; Cantallops et al. 2000), the effects of CPG15 deletion on both axonal and dendritic arborization are more subtle and are fully compensated for in the $\operatorname{cpg} 15 \mathrm{KO}$ mice by $2 \mathrm{mo}$ of age. There are precedents for in vivo RNAi-mediated interventions and overexpression studies during development resulting in deficits not observed in knockout animals. For example, in the case of the doublecortin $(D C X)$ gene, acute knockdown early in development results in severe cortical lamination deficits, but in the knockout mouse, cortical lamination is normal (Bai et al. 2003). Even in the case of neurotrophins and their receptors, mutant mouse studies repeatedly show less overt phenotypes than might be expected for molecules considered critical for both neuronal survival and differentiation (Conover and Yancopoulos 1997). Molecules such as neuroligins that exhibit robust synaptogenic activity in coculture assays (Scheiffele et al.
2000) when completely eliminated in knockout mice fail to affect synapse numbers in vivo (Varoqueaux et al. 2006). Rather, neuroligin knockout mice show subtle synaptic deficits that are likely associated with selection of specific synapse types. When a gene product is missing from the outset, compensatory or redundant molecules and mechanisms may be brought into play before developmental programs are significantly compromised. This is likely to be particularly true for molecules involved in synapse formation and maturation due to the multiplicity of players involved (Brose 2009). This does not mean that the function of these molecules is completely interchangeable; rather, combinations of these molecules likely instruct specificity and diversity of synaptogenesis. In the cpg $15 \mathrm{KO}$, other molecules can apparently replace the trophic function of CPG15, resulting in normal cell number and structure. cpg15 KO neurons can form functional synapses with normal ultrastructure, indicating that CPG15 is also dispensable for synaptogenesis and synaptic growth. However, the delay in arbor growth and synapse development and the reduced stability of dendritic spines in the adult suggest that CPG15 plays a critical regulatory role in determining which synaptogenic events are stabilized and maintained.

\section{A biphasic role for CPG15 in arbor and synapse development}

During development, an increased rate of growth is often equated with maturation, but this interpretation may be too simplistic. There are many examples throughout the developing brain where maturation proceeds first through the initial establishment of exuberant and/or promiscuous dendritic and axonal branches and synapses, followed by a period of dynamic refinement and sculpting during which inappropriate contacts and branches are eliminated and appropriate ones are stabilized and elaborated (Kano and Hashimoto 2009). The cpg15 KO mouse exhibits a lack of initial exuberance in dendritic branch elaboration and synapse formation in areas of the developing brain investigated in this study. This results, in some cases, in the superficial appearance of "mature"-looking branches from an early age; however, these arbors have not matured in the sense that they have not undergone the same extensive remodeling as their wild-type counterparts. We would not interpret this as a precocious maturation, since a true precocious maturation would go through the same sequence of events as a normally developing animal, except earlier. Consistently, our data show that this is not the case for the cpg 15 KO mouse. Instead, we show that the cpg 15 KO never reaches the phase in development where processes and synapses become exuberant enough for largescale sculpting and refinement to be observed.

This interpretation is also consistent with the developmental regulation of $\operatorname{cpg} 15$ expression. In the visual system early in development, cpg15 expression is activityindependent (Corriveau et al. 1999; Lee and Nedivi 2002). Promiscuous early expression of CPG15 may result in the establishment of large arbors and many synapses, effective substrates upon which activity-dependent mechanisms can later work to sculpt circuits by choosing which 
synapses and branches to keep and which to prune. During these later periods, cpg15 expression becomes activity-dependent, perhaps allowing CPG15 to function in the stabilization of appropriate activity-selected synaptic partners and branches.

\section{CPG15 as a synapse stabilization factor}

Despite lower spine synapse density in the hippocampal DG of 2-mo-old cpg15 KO mice as compared with wildtype controls, spine counts in this region were normal. This suggests that $\operatorname{cpg} 15 \mathrm{KO}$ neurons have a larger percentage of spines without well-defined synaptic structures. Previous serial EM reconstruction studies have found little evidence of spines without synaptic specializations in adult animals (Harris et al. 1989; Harris and Kater 1994), and developmental studies in dissociated and organotypic slice cultures suggest that synaptic molecules can cluster at pre- and post-synaptic sites shortly after contact (Vardinon Friedman et al. 2000; Okabe et al. 2001). Imaging studies combined with retrospective EM show that the latency to formation of synaptic structures on nascent spines varies from several hours up to $4 \mathrm{~d}$ (Knott et al. 2006; Nägerl et al. 2007; Zito et al. 2009). Thus, spine formation can lead to rapid synapse recruitment and stabilization, but does not necessarily do so. The choice between synapse stabilization and elimination is likely guided by specific signaling molecules that ensure the selection of optimal synaptic partners and efficient circuit wiring. Reduction in spine synapse density in the cpg15 KO mice without a change in spine number may reflect an increase in spine-like protrusions that fail to stabilize nascent synapses. Indeed, when spine and spine synapse densities are analyzed at a later age, cpg15 KO mice prune spines, but not spine synapses, suggesting selective pruning of unstabilized, synapseless spines. Furthermore, in vivo time-lapse imaging of dendritic spines on cortical L5 neurons of wild-type and cpg15 KO mice shows that while overall spine dynamics on cpg15 KO neurons are normal, there is a bias toward increased spine loss, suggesting that spines are less well maintained. The fact that this can be observed even in the adult on an individual cell basis further suggests an acute requirement for CPG15 in spine and perhaps synapse stabilization.

During development, synapses have been shown to act as anchoring points for growing dendritic and axonal branches, facilitating branch extension and giving pause to branch retractions, so that arbor dynamics are strongly influenced by synapse stabilization (Meyer and Smith 2006; Ruthazer et al. 2006). It is therefore likely that delayed axon and dendrite development in the cpg $15 \mathrm{KO}$ is directly linked to the delay in functional synapse formation and maturation. This interpretation is consistent with findings from previous overexpression studies in the developing Xenopus that showed that CPG15 coordinately promotes synaptic maturation and arbor growth (Cantallops et al. 2000; Javaherian and Cline 2005) and that increased arbor growth is due to fewer branch retractions (Cantallops et al. 2000).

In rodents, exposure to an enriched environment improves performance in learning and memory tasks and increases dendritic spine density (van Praag et al. 2000), suggesting that changes in connectivity may be a cellular correlate of improved performance. In vivo imaging studies show that dendritic spines retain dynamic qualities even in the adult brain (Grutzendler et al. 2002; Trachtenberg et al. 2002) and that activity appears to play an instructive role in this remodeling. Spines appear and disappear in hippocampal slices after electrical stimulation as well as in vivo in response to experience (for review, see Bhatt et al. 2009). Thus, it seems that the dynamic nature of dendritic spines provides the capacity for local circuit restructuring in response to normal day-to-day levels of activity. In the same way that synapse formation on growing axons and dendrites provides an anchor for arbor stabilization during development, synapse formation on dynamic spines could serve to consolidate nascent connections in a mature circuit. This suggests that CPG15 could continue to play a role as a synaptic stabilizing factor, extending past developmental circuit wiring and into optimization of adult circuitry. cpg15 KO neurons may be unable to stabilize connections in the adult and thus may have to rely on an initial set of synapses stochastically formed during development.

Based on our analysis of the cpg15 KO mouse, we propose that CPG15 acts to stabilize nascent synapses on dendritic spines, resulting in spine and arbor stabilization and synaptic maturation. Neuroligins were recently proposed to act as a signal for the validation of excitatory versus inhibitory synapses. Rather than mediating synapse formation per se, neuroligins signal whether a transiently initiated connection stays or goes (Chubykin et al. 2007). It is intriguing to consider that since CPG15 is expressed and can be externalized in response to activity (Cantallops and Cline 2008), it could provide a saliency signal for selective stabilization of active synapses. While synaptic connections can form without CPG15, they are slower to form and are not optimized by activity patterns that are required for efficient learning. $\operatorname{cpg} 15 \mathrm{KO}$ mice are capable of learning with increased trials, and their sensory and motor functions appear to be within the normal range, suggesting that many behaviors required for survival are hardwired through highly overlapping and redundant mechanisms. Only when peak performance is desired does the role of activity-dependent tuning mediated by molecules such as CPG15 become starkly evident.

The subtle deficit we observed in relation to synapse stabilization allowed us to probe the consequences of CPG15 functional deletion on circuit properties and behavior without the confounding aspects of complex phenotypes commonly found in general knockout mice. Our results lead us to speculate that the inefficient learning seen in cpg $15 \mathrm{KO}$ mice derives from a diminished capacity for selective synapse stabilization.

\section{Materials and methods}

\section{Generation of the cpg15 KO mice}

All animal work was approved by the Massachusetts Institute of Technology Committee on Animal Care and conforms to NIH 
guidelines for the use and care of vertebrate animals. To allow conditional deletion of the cpg15 gene using the Cre-loxP system, we generated floxed cpg15 mice. The targeting vector was constructed starting with a $13.7-\mathrm{kb}$ genomic fragment spanning a region of the cpg15 gene from the EcoRV site $0.2 \mathrm{~kb}$ upstream of exon 1 to the AflII site $4.7 \mathrm{~kb}$ downstream from exon 3, cloned from a C57BL/6 mouse BAC library (Genomic Systems). Exons 2 and 3 were floxed by replacing a 19-base-pair (bp) sequence between the SacI and KpnI sites $0.5 \mathrm{~kb}$ upstream of exon 2 with a 40-bp fragment containing lox $P$ and XhoI sites and inserting a 2.9-kb LFNT-TK cassette (gift of Kazu Nakazawa), consisting of a neomycin resistance (neo) gene flanked by two lox $P$ sites and two FRT sites, into the SacI site $0.9 \mathrm{~kb}$ downstream from exon 3. The diphtheria toxin A gene from pMCI DT-A (Yagi et al. 1990) was inserted at the end of the targeting vector for negative selection. The linearized targeting vector was electroporated into a C57BL/6 embryonic stem cell line. G418-resistant embryonic stem cell clones were tested for homologous recombination by Southern blot analysis using an internal probe and 5'and $3^{\prime}$-external probes. Embryonic stem cell clones showing the expected patterns were injected into blastocysts from BALB/c mice to obtain chimeric mice. Chimeras were bred with C57BL/ 6 mice to generate mice carrying the floxed cpg15 allele and neo gene $\left(\operatorname{cpg} 15^{\text {flox-neo/+ }}\right)$. The neo gene was then removed by injecting flippase cRNA synthesized in vitro from pOG-Flpe6 (Buchholz et al. 1998) into fertilized eggs from cpg15 ${ }^{\text {flox-neo/+ }}$ mice, thus generating floxed cpg15 mice without the neo gene in pure C57BL/6 background $\left(\operatorname{cpg} 15^{\text {flox/++}}\right)$. To generate general cpg15-null mice, $\operatorname{cpg} 15^{\text {flox/+ }}$ mice were crossed to an adenovirus EIIa promoter-driven Cre transgenic line in C57BL/6 background [Jackson Laboratory, B6.FVB-TgN(EIIa-cre)C5379Lmgd] (Lakso et al. 1996). Progeny of this cross that were heterozygous for the cpg15-null allele $\left(\operatorname{cpg} 15^{+/-}\right)$were intercrossed to obtain homozygous cpg15-null mice $\left(\operatorname{cpg} 15^{-/-}\right)$. The absence of floxed cpg15 genomic sequence, cpg15 mRNA, and CPG15 protein was confirmed by Southern blots of tail genomic DNA (Sambrook et al. 1989), Northern blots on brain RNA (Fujino et al. 2003), and Western blots, respectively. For Western blots, membrane proteinenriched fractions were prepared from the cerebral cortex and hippocampus of adult mice using the Mem-PER kit (Pierce) and PAGEprep advance kit (Pierce). Forty micrograms of protein was resolved by $15 \%$ SDS-PAGE, transferred to a nitrocellulose membrane, incubated with rabbit anti-CPG15 $(1: 100)$ and then HRP-conjugated goat anti-rabbit IgG (1:50,000; Jackson ImmunoResearch), and visualized by chemiluminescence (Pierce). Antibodies against CPG15 were generated by immunizing rabbits with peptides corresponding to amino acids 28-40 and 99116 and were affinity-purified with the immunizing peptides (Open Biosystems).

cpg15 KO lines were maintained as cpg $15^{+/-} \times \operatorname{cpg} 15^{+/-}$crosses. Genotyping was done by tail DNA PCR. Wild-type forward primer (5'-CGCAGCCCAATCTGCATTC-3'; $0.13 \mathrm{pmol} / \mu \mathrm{L})$, cpg15-null forward primer (5'-GTTGTGGTCTTCCAAAGACC-3'; $0.5 \mathrm{pmol} /$ $\mu \mathrm{L})$, and common reverse primer (5'-GGAGCAGCGAGATCT CCTT-3'; $0.5 \mathrm{pmol} / \mu \mathrm{L}$ ) were used to amplify a 230 -bp wild-type band and a 350-bp cpg15-null band. Mice were housed under a 12-h light/dark cycle with ad libitum access to food and water.

\section{Data collection and analysis}

All quantifications comparing wild-type and cpg15 KO mice were done blind to genotype. Statistical analysis was done using StatView software (SAS Institute). Unless otherwise stated, Student's unpaired $t$-test was used for two-group comparisons, and analysis of variance (ANOVA) and Student-Newman-Keuls post hoc analysis were used for comparisons involving more than two groups. Error bars are standard error of the mean unless otherwise stated.

\section{Brain measurements}

Age-matched males were perfused with phosphate-buffered saline (PBS) and then with $4 \%$ paraformaldehyde in PBS. Brains were dissected out, weighed, and measured with vernier calipers. After overnight post-fixation at $4^{\circ} \mathrm{C}$, brains were cryoprotected in $30 \%$ sucrose in PBS, frozen in powdered dry ice, and sectioned coronally at $40 \mu \mathrm{m}$ with a cryostat (Leica). Every sixth section was stained with cresyl violet. For volume measurements, the area on each section was measured using the point-counting method, and the total volume was estimated based on Cavalieri's rule (Williams et al. 2003). Cell density was measured by the three-dimensional counting method (Williams and Rakic 1988).

\section{Labeling retinal ganglion projections in the LGN}

Mice younger than P9 were anesthetized by hypothermia or with $2.5 \%$ Avertin $(250 \mathrm{mg} / \mathrm{kg}$ intraperitoneally [i.p.]) at later ages. Animals received an intravitreal injection of wheat germ agglutinin (WGA) conjugated to Alexa Fluor $555(1 \mathrm{mg} / \mathrm{mL}$; Molecular Probes) in the left eye and WGA-Alexa Fluor 488 in the right eye. For injections prior to natural eye opening, fused eyelids were separated or cut to expose the temporal region of the eye. After $24 \mathrm{~h}$, animals were perfused with $4 \%$ paraformaldehyde in PBS. Brains were removed and post-fixed overnight and then coronally sectioned at $75 \mu \mathrm{m}$ using a vibratome.

LGN images were acquired with an epifluorescence microscope (Nikon) using a 10×/N.A. 0.3 objective lens (Nikon). Four successive sections, representing the middle third of the LGN, were selected. Background fluorescence was subtracted, and grayscale images were normalized (0-255) using ImageJ (http:// rsb.info.nih.gov/ij). Grayscale images were converted into binary high-contrast black-and-white images by employing a threshold procedure that distinguishes signal from residual background fluorescence (Muir-Robinson et al. 2002; Torborg and Feller 2004) Contralateral (pseudo-colored green) and ipsilateral signals (pseudocolored magenta) were superimposed (Fig. 2). An outline of the entire LGN was drawn, and the area was measured. The extent of overlapping projections was determined by counting pixels that contained both green and magenta signal, represented as white.

\section{Diolisitic labeling in the hippocampus}

Brain sections from P7, P15, and 2-mo-old mice were processed for diolistic labeling as described (Grutzendler et al. 2003) with the following modifications. After rapidly perfusing P15 and 2mo-old mice with $4 \%$ paraformaldehyde in PBS ( $40 \mathrm{~mL}$ in $2 \mathrm{~min}$ ), brains were dissected out and post-fixed for $10 \mathrm{~min}$ at room temperature. P7 brains were removed without perfusion and then fixed in 4\% PFA for 10 min at room temperature. All brains were coronally sectioned at $100 \mu \mathrm{m}$ with a vibratome and stored in $30 \%$ sucrose in PBS. Bullets were prepared by coating tungsten particles (1.7 $\mu \mathrm{m}$; Bio-Rad) with DiI (Molecular Probes), then loaded into Tefzel tubing (Bio-Rad) pretreated with polyvinylpyrrolidone ( $1 \mathrm{mg} / \mathrm{mL}$ in isopropanol; Sigma), and dried with N2. Brain sections were covered with a tissue culture insert with a $3-\mu \mathrm{m}$ pore size (Greiner) and then shot with DiI-coated particles using a Helios gene gun system (Bio-Rad) set at 160 psi. Sections were post-fixed in $4 \%$ paraformaldehyde/ $30 \%$ sucrose in PBS overnight and mounted on glass slides with Fluoromount-G (Sourthern Biotech). Neurons were imaged with a Nikon PCM 2000 confocal microscopy system controlled by Simple PCI software (Compix, Inc., Image System) or an Olympus FluoView 
300 laser-scanning confocal microscope and FluoView 500 acquisition software. Stacks of 26 images at $2-\mu \mathrm{m}$ intervals, spanning $50 \mu \mathrm{m}$ in thickness, were obtained with a $20 \times$ objective lens. Images were analyzed using Object-Image software (http://simon.bio. uva.nl/object-image.html) with Morphometry Macros (Ruthazer and Cline 2002) or with Neurolucida and Neurolucida Explorer software (MBF Bioscience). Total dendritic branch length and branch tip number within the imaging volume were quantified for dendritic arbors of DG granule cells.

\section{Electrophysiology}

Hippocampi of P7 or 2-mo-old mice were isolated, and 300- $\mu \mathrm{m}$ slices were prepared with a vibratome (World Precision Instruments) in ice-cold cutting solution containing $238 \mathrm{mM}$ sucrose, $26 \mathrm{mM} \mathrm{NaHCO}_{3}, 10 \mathrm{mM}$ glucose, $2.5 \mathrm{mM} \mathrm{KCl}, 1 \mathrm{mM} \mathrm{NaH}_{2} \mathrm{PO}_{4}$, $3 \mathrm{mM} \mathrm{MgSO}_{4}$, and $1 \mathrm{mM} \mathrm{CaCl}_{2}$ constantly bubbled with $95 \%$ $\mathrm{O}_{2} / 5 \% \mathrm{CO}_{2}$. The slices were transferred to a holding chamber filled with artificial cerebrospinal fluid (ACSF) containing $119 \mathrm{mM} \mathrm{NaCl}, 26 \mathrm{mM} \mathrm{NaHCO}_{3}, 10 \mathrm{mM}$ glucose, $2.5 \mathrm{mM} \mathrm{KCl}$, $1 \mathrm{mM} \mathrm{NaH}_{2} \mathrm{PO}_{4}, 1.3 \mathrm{mM} \mathrm{MgSO}_{4}$, and $2.5 \mathrm{mM} \mathrm{CaCl}_{2}$ constantly bubbled with $95 \% \mathrm{O}_{2} / 5 \% \mathrm{CO}_{2}$ and were recovered for half an hour at $32^{\circ} \mathrm{C}$ and then for half an hour at room temperature. Slices were placed in a recording chamber continuously perfused with $32^{\circ} \mathrm{C}$ ACSF bubbled with $95 \% \mathrm{O}_{2} / 5 \% \mathrm{CO}_{2}$, plus $100 \mu \mathrm{M}$ picrotoxin and $1 \mu \mathrm{M}$ tetrodotoxin to isolate mEPSCs. Whole-cell recordings were performed with patch pipettes (5-7 M 2 ) containing $130 \mathrm{mM}$ K-gluconate, $4 \mathrm{mM} \mathrm{KCl}, 2 \mathrm{mM} \mathrm{NaCl}, 10 \mathrm{mM}$ Hepes, $0.2 \mathrm{mM}$ EGTA, $4 \mathrm{mM}$ ATP-Mg, $0.3 \mathrm{mM}$ GTP-Tris, $7 \mathrm{mM}$ phosphocreatine-Tris, and $10 \mathrm{mM}$ sucrose (pH 7.25, $290 \mathrm{mOsm})$. Neurons in $\mathrm{CAl}$ or dentate were patched under visual guidance with a Nikon microscope equipped with IR/DIC optics using a black-and-white CCD camera (CCD-300IFG, Dage-MTI). Current traces were collected using an AxoPatch 2B amplifier (Axon), digitized at $5 \mathrm{kHz}$ by a Digidata 1322A (Axon), and analyzed offline using Clampfit software (Axon). At least $150 \mathrm{mEPSCs}$, thresholded at $6 \mathrm{pA}$, were recorded at $-70 \mathrm{mV}$ from each cell. Twenty micromolar 6,7Dinitroquinoxaline-2,3-dione was applied during some recordings to verify AMPAR mEPSCs.

\section{$E M$}

Two-month-old and 9-mo-old male littermates were perfused, and brains were fixed as described (Diano et al. 2006). Ultrathin sections were prepared as described (Diano et al. 2006) from stratum radiatum of $\mathrm{CA} 1$ and $\mathrm{CA} 3$ and the molecular layer of the DG. Spine and spine synapse density was calculated by unbiased stereological methods based on the dissector technique (Diano et al. 2006). PSD length was measured from 100-150 spine synapses in 10 nonoverlapping sections and averaged for each animal.

\section{Two-photon imaging}

Cranial window implantation and multiphoton imaging were done essentially as described (Lee et al. 2008). Mice (6-8 wk of age) were implanted with cranial windows and imaged $2-3$ wk after surgery at 4 -d intervals. For imaging, mice were anesthetized with $1.25 \%$ avertin $(250 \mathrm{mg}$ per kilogram of body weight, i.p.). Anesthesia was monitored by breathing rate and foot-pinch reflex, and additional doses of anesthetic were administered during the imaging session as needed. Two-photon imaging was performed using a custom-built microscope modified for in vivo imaging by inclusion of a custom-made stereotaxic restraint affixed to a stage insert and custom acquisition software. The light source for two-photon excitation was a commercial Mai Tai HP titanium:sapphire laser (Spectra-Physics) pumped by a $14-\mathrm{W}$ solid-state laser delivering 100 -fsec pulses at a rate of $80 \mathrm{MHz}$, with the power delivered to the objective ranging from $\sim 37$ to 50 $\mathrm{mW}$, depending on imaging depth. $Z$ resolution was obtained with a piezo actuator positioning system (Piezosystem Jena) mounted to the objective. The excitation wavelength was set to $950 \mathrm{~nm}$, with the excitation signal passing through a $20 \times, 1.0$ numerical aperture water immersion objective (Plan-Apochromat, Zeiss) and collected after a barrier filter by a photomultiplier tube.

Given the sparse density of GFP expression in the thy1-GFP-S line, typically, a dendritic segment from one L5 pyramidal neuron (and a maximum of two) was imaged per animal. Cells mapped to the visual cortex were then identified as L5 pyramidal neurons based on their depth from the pial surface and morphology. Blood vessel pattern maps were used to locate the cells and dendritic branches throughout the imaging sessions. Low-resolution image stacks $(512 \times 512$ pixels, $1 \mu \mathrm{m} /$ pixel $X-Y$ resolution, $5-\mu \mathrm{m} Z$-step size) were used to identify cell type and depth. High-resolution image stacks $(768 \times 768$ pixels, $0.2 \mu \mathrm{m} /$ pixel $X-Y$ resolution, $0.7-\mu \mathrm{m} Z$-step size) were used to capture spine dynamics on L5 dendrites in L1.

\section{Dendritic spine analysis}

Image stacks were aligned such that the presence or absence of an individual spine at a given location on the dendrite could be determined in each session. Spines were scored only if they protruded $>0.4 \mu \mathrm{m}$ from the dendritic shaft and were projecting into the $X Y$ plane. Long thin spines without bulbous heads were excluded from analysis, since they were always transient and were not significantly different in number or dynamics between genotypes. The rate of spine gain and spine loss was defined as the percentage of spines appearing (spine gain) or disappearing (spine loss) in a session compared with the total number of spines in the previous session. Dynamic spines were sorted into the following categories: Transient spines were those that appeared for no more than one or two imaging sessions then disappeared, or that disappeared and reappeared through the imaging period; newpersistent spines were defined as those that were not present in the first session and subsequently gained for at least the last two sessions; and lost-persistent spines were defined as those that were present in at least the first two sessions and then were lost for the remaining sessions. Analysis was performed using V3D software (Peng et al. 2010) by an observer blind to genotype.

\section{Behavioral tests}

Male littermates between 3 and 6 mo of age were used for behavioral experiments, unless otherwise noted.

Grip strength test Mice were allowed to hold on to a wire attached to a spring scale (Pesola) and were pulled horizontally by their tail. Maximal pulling force before releasing the wire was recorded. Five trials were done for each mouse, and the average was calculated for best three.

Rotarod test Mice were placed on an accelerating rotarod, and latency to falling from the rod was recorded. Each trial lasted for a maximum of $8 \mathrm{~min}$, during which the rotation speed increased linearly from $2.5 \mathrm{rpm}$ to $40 \mathrm{rpm}$. Three trials were done per day for two consecutive days.

Open field test Mice were placed in the center of an open field $(40 \times 40 \mathrm{~cm})$ and allowed to move freely for $30 \mathrm{~min}$. Their activity was monitored by a Digiscan system in 1-min bins and was analyzed by Versa Max software (AccuScan Instruments). Data were averaged for $30 \mathrm{~min}$. 
Hot plate test Mice were placed on a hot plate preheated to $55^{\circ} \mathrm{C}$. Latency to paw lifting or sudden movement was recorded. All mice responded within $15 \mathrm{sec}$.

Fear conditioning One-trial fear conditioning was done as described (Zeng et al. 2001) with modifications described in the Supplemental Material. Memory was tested after $1 \mathrm{~h}$ and $24 \mathrm{~h}$ of the conditioning trial for contextual memory and after $25 \mathrm{~h}$ for tone-dependent memory. For repeated training, conditioning sessions with one tone-shock pairing were given on days 1, 3, and 5, and a session with three tone-shock pairings (each pair starting at 1,2 , and 3 min after placement in chamber) was given on day 7 . Context and tone tests were done $24 \mathrm{~h}$ and $25 \mathrm{~h}$, respectively, after each conditioning session. For one-trial fear conditioning, 4- to 9mo-old male mice were used.

Morris water maze visible platform test The visible platform test was done essentially as described (Zeng et al. 2001). The pool was $150 \mathrm{~cm}$ in diameter, with water at room temperature $\left(21^{\circ} \mathrm{C}-\right.$ $22^{\circ} \mathrm{C}$ ). The platform was $10 \mathrm{~cm}$ in diameter. Each mouse was trained three trials per day, with intertrial intervals of $\sim 30 \mathrm{~min}$. The platform position was changed for each trial. In each trial, the mouse was allowed to swim until it found the platform or until $60 \mathrm{sec}$ had elapsed, at which point the mouse was guided to the platform. The mouse was allowed to sit on the platform for $30 \mathrm{sec}$ before being picked up.

\section{Acknowledgments}

We thank Matthew Wilson, Richard Morris, and many members of the Tonegawa, Bear, and Nedivi laboratories for helpful discussions; Kazu Nakazawa and Heather Hinds from the Tonegawa laboratory for providing the LFNT cassette and C57BL/6 embryonic stem cells and suggestions on knockout mouse generation; Susan Su for help with BrdU labeling experiments; Marla Feller for advice on LGN analysis; Albert Hung for teaching diolistic labeling; Weifeng Xu, Gordon Smith, Arnold Heynen, and Kensuke Futai for advice on electrophysiology experiments; Thomas McHugh, Guiquan Chen, and Tsuyoshi Miyakawa for suggestions on behavioral experiments; Michael Ragion, David Nguyen, and Matthew Wilson for sharing unpublished results on in vivo recordings; and members of the Nedivi laboratory for critical reading of the manuscript. This research was supported by funding to E.N. from the National Eye Institute (RO1 EY011894) and to T.L.H. from the National Institute of Health Director's Pioneer Award (DP1 OD006850) and the National Institute of Diabetes and Digestive and Kidney Diseases (DK080000).

\section{References}

Bai J, Ramos RL, Ackman JB, Thomas AM, Lee RV, LoTurco JJ. 2003. RNAi reveals doublecortin is required for radial migration in rat neocortex. Nat Neurosci 6: 1277-1282.

Bhatt DH, Zhang S, Gan WB. 2009. Dendritic spine dynamics. Annu Rev Physiol 71: 261-282.

Brose N. 2009. Synaptogenic proteins and synaptic organizers: 'Many hands make light work.' Neuron 61: 650-652.

Brückner G, Mares V, Biesold D. 1976. Neurogenesis in the visual system of the rat. An autoradiographic investigation. I Comp Neurol 166: 245-255.

Buchholz F, Angrand PO, Stewart AF. 1998. Improved properties of FLP recombinase evolved by cycling mutagenesis. Nat Biotechnol 16: 657-662.

Cantallops I, Cline HT. 2008. Rapid activity-dependent delivery of the neurotrophic protein CPG15 to the axon surface of neurons in intact Xenopus tadpoles. Dev Neurobiol 68: 744759.

Cantallops I, Haas K, Cline HT. 2000. Postsynaptic CPG15 promotes synaptic maturation and presynaptic axon arbor elaboration in vivo. Nat Neurosci 3: 1004-1011.

Chubykin AA, Atasoy D, Etherton MR, Brose N, Kavalali ET, Gibson JR, Südhof TC. 2007. Activity-dependent validation of excitatory versus inhibitory synapses by neuroligin-1 versus neuroligin-2. Neuron 54: 919-931.

Conover JC, Yancopoulos GD. 1997. Neurotrophin regulation of the developing nervous system: Analyses of knockout mice. Rev Neurosci 8: 13-27.

Corriveau R, Shatz CJ, Nedivi E. 1999. Dynamic regulation of cpg15 during activity-dependent synaptic development in the mammalian visual system. I Neurosci 19: 7999-8008.

Diano S, Farr SA, Benoit SC, McNay EC, da Silva I, Horvath B, Gaskin FS, Nonaka N, Jaeger LB, Banks WA, et al. 2006. Ghrelin controls hippocampal spine synapse density and memory performance. Nat Neurosci 9: 381-388.

Diaz E, Ge Y, Yang YH, Loh KC, Serafini TA, Okazaki Y, Hayashizaki Y, Speed TP, Ngai J, Scheiffele P. 2002. Molecular analysis of gene expression in the developing pontocerebellar projection system. Neuron 36: 417-434.

Feng G, Mellor RH, Bernstein M, Keller-Peck C, Nguyen QT, Wallace M, Nerbonne JM, Lichtman JW, Sanes JR. 2000. Imaging neuronal subsets in transgenic mice expressing multiple spectral variants of GFP. Neuron 28: 41-45.

Flavell SW, Greenberg ME. 2008. Signaling mechanisms linking neuronal activity to gene expression and plasticity of the nervous system. Annu Rev Neurosci 31: 563-590.

Fujino T, Lee WA, Nedivi E. 2003. Regulation of cpg15 by signaling pathways that mediate synaptic plasticity. Mol Cell Neurosci 24: 538-554.

Gomperts SN, Carroll R, Malenka RC, Nicoll RA. 2000. Distinct roles for ionotropic and metabotropic glutamate receptors in the maturation of excitatory synapses. I Neurosci 20: 2229-2237.

Grutzendler J, Kasthuri N, Gan W-B. 2002. Long-term dendritic spine stability in the adult cortex. Nature 420: 812-816.

Grutzendler J, Tsai J, Gan WB. 2003. Rapid labeling of neuronal populations by ballistic delivery of fluorescent dyes. Methods 30: 79-85.

Harris KM, Kater SB. 1994. Dendritic spines: Cellular specializations imparting both stability and flexibility to synaptic function. Annu Rev Neurosci 17: 341-371.

Harris KM, Jensen FE, Tsao BH. 1989. Ultrastructure, development and plasticity of dendritic spine synapses in area CA1 of the rat hippocampus: Extending our vision with serial electron microscopy and three-dimensional analyses. In The hippocampus: New vistas (ed.V Chan-Palay,C Kohler). Liss, New York.

Hevroni D, Rattner A, Bundman M, Lederfein D, Gbarah A, Mangelus M, Silverman M, Kedar H, Naor C, Kornuc M, et al. 1998. Hippocampal plasticity involves extensive gene induction and multiple cellular mechanisms. J Mol Neurosci 10: $75-98$.

Holtmaat AJ, Trachtenberg JT, Wilbrecht L, Shepherd GM, Zhang X, Knott GW, Svoboda K. 2005. Transient and persistent dendritic spines in the neocortex in vivo. Neuron 45: 279-291.

Holtmaat A, Wilbrecht L, Knott GW, Welker E, Svoboda K. 2006. Experience-dependent and cell-type-specific spine growth in the neocortex. Nature 441: 979-983.

Hua JY, Smith SJ. 2004. Neural activity and the dynamics of central nervous system development. Nat Neurosci 7: 327332. 
Javaherian A, Cline HT. 2005. Coordinated motor neuron axon growth and neuromuscular synaptogenesis are promoted by CPG15 in vivo. Neuron 45: 505-512.

Kano M, Hashimoto K. 2009. Synapse elimination in the central nervous system. Curr Opin Neurobiol 19: 154-161.

Knott GW, Holtmaat A, Wilbrecht L, Welker E, Svoboda K. 2006. Spine growth precedes synapse formation in the adult neocortex in vivo. Nat Neurosci 9: 1117-1124.

Konur S, Yuste R. 2004. Imaging the motility of dendritic protrusions and axon terminals: Roles in axon sampling and synaptic competition. Mol Cell Neurosci 27: 427-440.

Lakso M, Pichel JG, Gorman JR, Sauer B, Okamoto Y, Lee E, Alt FW, Westphal H. 1996. Efficient in vivo manipulation of mouse genomic sequences at the zygote stage. Proc Natl Acad Sci 93: 5860-5865.

Lee WCA, Nedivi E. 2002. Extended plasticity of visual cortex in dark-reared animals may result from prolonged expression of genes like cpg15. J Neurosci 22: 1807-1815.

Lee WCA, Huang H, Feng G, Sanes JR, Brown EN, So PT, Nedivi E. 2006. Dynamic remodeling of dendritic arbors in GABAergic interneurons of adult visual cortex. PLoS Biol 4: e29. doi: 10.1371/journal.pbio.0040029.

Lee WCA, Chen JL, Huang H, Leslie JH, Amitai Y, So PT, Nedivi E. 2008. A dynamic zone defines interneurons remodeling in the adult neocortex. Proc Natl Acad Sci 105: 19968-19973.

Leslie JH, Nedivi E. 2011. Activity-regulated genes as mediators of neural circuit plasticity. Prog Neurobiol 94: 223-237.

Loebrich S, Nedivi E. 2009. The function of activity-regulated genes in the nervous system. Physiol Rev 89: 1079-1103.

Markus EJ, Petit TL. 1987. Neocortical synaptogenesis, aging, and behavior: Lifespan development in the motor-sensory system of the rat. Exp Neurol 96: 262-278.

McAllister KA. 2007. Dynamic aspects of CNS synapse formation. Annu Rev Neurosci 30: 425-450.

Meyer MP, Smith SJ. 2006. Evidence from in vivo imaging that synaptogenesis guides the growth and branching of axonal arbors by two distinct mechanisms. I Neurosci 26: 36043614.

Muir-Robinson G, Hwang BJ, Feller MB. 2002. Retinogeniculate axons undergo eye-specific segregation in the absence of eyespecific layers. J Neurosci 22: 5259-5264.

Naeve GS, Ramakrishnan M, Rainer K, Hevroni D, Citri Y, Theill LE. 1997. Neuritin: A gene induced by neural activity and neurotrophins that promotes neuritogenesis. Proc Natl Acad Sci 94: 2648-2653.

Nägerl UV, Köstinger G, Anderson JC, Martin KA, Bonhoeffer T. 2007. Protracted synaptogenesis after activity-dependent spinogenesis in hippocampal neurons. J Neurosci 27: 81498156.

Nedivi E, Hevroni D, Naot D, Israeli D, Citri Y. 1993. Numerous candidate plasticity-related genes revealed by differential cDNA cloning. Nature 363: 718-722.

Nedivi E, Fieldust S, Theill LE, Hevron D. 1996. A set of genes expressed in response to light in the adult cerebral cortex and regulated during development. Proc Natl Acad Sci 93: 20482053.

Nedivi E, Wu GY, Cline HT. 1998. Promotion of dendritic growth by CPG15, an activity-induced signaling molecule. Science 281: $1863-1866$.

Okabe S, Miwa A, Okado H. 2001. Spine formation and correlated assembly of presynaptic and postsynaptic molecules. J Neurosci 21: 6105-6114.

Peng H, Ruan Z, Long F, Simpson JH, Myers EW. 2010. V3D enables real-time $3 \mathrm{D}$ visualization and quantitative analysis of large-scale biological image data sets. Nat Biotechnol 28: 348-353.
Putz U, Harwell C, Nedivi E. 2005. Soluble CPG15 expressed during early development rescues cortical progenitors from apoptosis. Nat Neurosci 8: 322-331.

Rahimi O, Claiborne BJ. 2007. Morphological development and maturation of granule neuron dendrites in the rat dentate gyrus. Prog Brain Res 163: 167-181.

Ruthazer ES, Cline HT. 2002. Multiphoton imaging of neurons in living tissue: Acquisition and analysis of time-lapse morphological data. Real-Time Imag 8: 175-188.

Ruthazer ES, Li J, Cline HT. 2006. Stabilization of axon branch dynamics by synaptic maturation. J Neurosci 26: 3594-3603.

Sambrook J, Fritsch EF, Maniatis T. 1989. Molecular cloning: A laboratory manual. Cold Spring Harbor Laboratory Press, Cold Spring Harbor, NY.

Scheiffele P, Fan J, Choih J, Fetter R, Serafini T. 2000. Neuroligin expressed in nonneuronal cells triggers presynaptic development in contacting axons. Cell 101: 657-669.

Torborg CL, Feller MB. 2004. Unbiased analysis of bulk axonal segregation patterns. I Neurosci Methods 135: 17-26.

Trachtenberg JT, Chen BE, Knott GW, Feng G, Sanes JR, Welker E, Svoboda K. 2002. Long-term in vivo imaging of experience-dependent synaptic plasticity in adult cortex. Nature 420: 788-794.

van Praag H, Kempermann G, Gage FH. 2000. Neural consequences of environmental enrichment. Nat Rev Neurosci 1: 191-198.

Vardinon Friedman H, Bresler T, Garner CC, Ziv NE. 2000. Assembly of new individual excitatory synapses: Time course and temporal order of synaptic molecule recruitment. Neuron 27: 57-69.

Varoqueaux F, Aramuni G, Rawson RL, Mohrmann R, Missler M, Gottmann K, Zhang W, Sudhof TC, Brose N. 2006. Neuroligins determine synapse maturation and function. Neuron 51: 741-754.

Verhage M, Maia AS, Plomp JJ, Brussaard AB, Heeroma JH, Vermeer $\mathrm{H}$, Toonen RF, Hammer RE, van den Berg TK, Missler M, et al. 2000. Synaptic assembly of the brain in the absence of neurotransmitter secretion. Science 287: 864-869.

Williams RW, Rakic P. 1988. Three-dimensional counting: An accurate and direct method to estimate numbers of cells in sectioned material. J Comp Neurol 278: 344-352.

Williams RW, von Bartheld CS, Rosen GD. 2003. Counting cells in sectioned material: Suite of techniques, tools, and tips. Curr Protoc in Neurosci 1.11.1-1.11.29. doi: 10.1002/0471142301. ns0111s24.

Yagi T, Ikawa Y, Yoshida K, Shigetani Y, Takeda N, Mabuchi I, Yamamoto T, Aizawa S. 1990. Homologous recombination at c-fyn locus of mouse embryonic stem cells with use of diphtheria toxin A-fragment gene in negative selection. Proc Nat1 Acad Sci 87: 9918-9922.

Zeng H, Chattarji S, Barbarosie M, Rondi-Reig L, Philpot BD, Miyakawa T, Bear MF, Tonegawa S. 2001. Forebrain-specific calcineurin knockout selectively impairs bidirectional synaptic plasticity and working/episodic-like memory. Cell 107: 617-629.

Zito K, Scheuss V, Knott G, Hill T, Svoboda K. 2009. Rapid functional maturation of nascent dendritic spines. Neuron 61: 247-258. 


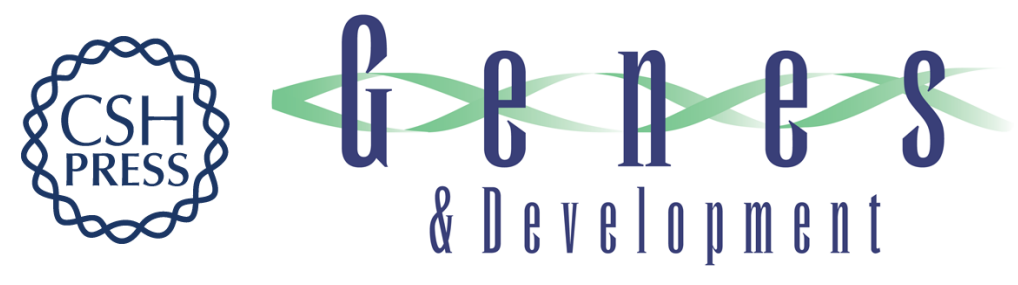

\section{CPG15 regulates synapse stability in the developing and adult brain}

Tadahiro Fujino, Jennifer H. Leslie, Ronen Eavri, et al.

Genes Dev. 2011, 25:

Access the most recent version at doi:10.1101/gad.176172.111

Supplemental Material

References

This article cites 59 articles, 15 of which can be accessed free at: http://genesdev.cshlp.org/content/25/24/2674.full.html\#ref-list-1

\section{License}

Email Alerting Service

http://genesdev.cshlp.org/content/suppl/2011/12/21/25.24.2674.DC1 right corner of the article or click here.

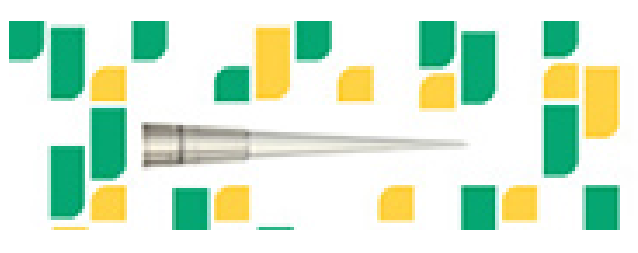

Focused on your science. 